VIEIRA, J.N., COELHO, E.G.A. e OLIVEIRA, D.A.A. Determinação sexual em aves via PCR. PUBVET, Londrina, V. 5, N. 3, Ed. 150, Art. 1011, 2011.

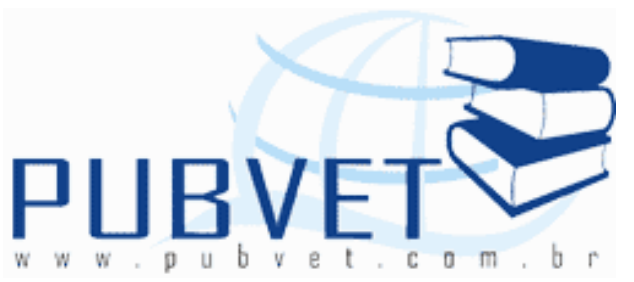

PUBVET, Publicações em Medicina Veterinária e Zootecnia.

\title{
Determinação sexual em aves via PCR
}

Juliana Nobre Vieira ${ }^{1 *}$, Eduardo Geraldo Alves Coelho ${ }^{2}$ e Denise Aparecida Andrade de Oliveira ${ }^{3}$

${ }^{1}$ Doutoranda, Departamento de Zootecnia, ${ }^{2}$ Co-orientador, ${ }^{3}$ Professora Associada da Escola de Veterinária da UFMG, Belo Horizonte, MG, Brasil. *Artigo referente à Dissertação de Mestrado, e-mail para correspondência: nobrevieira.j@gmail.com

\section{Resumo}

Este estudo avaliou a PCR como técnica molecular para determinar o sexo das aves empregando o par de primers alelo-específico, $\mathrm{P}_{2} / \mathrm{P}_{8}$, para o gene $\mathrm{CHD}$, localizado nos cromossomos sexuais $(\mathrm{Z} / \mathrm{W})$ das aves. O resultado eletroforético demonstrou dois alelos para as fêmeas $(Z W)$ e um nos machos $(Z Z)$, sendo heterogaméticos e homogaméticos, respectivamente. Foi observado que há variação entre os tamanhos dos pares de base $(\mathrm{pb})$ entre as espécies. Estes dados mostram que esta técnica é acurada e segura para a determinação sexual das aves, pois demonstram que o gene GHD está conservado nas aves. Palavras-chave: determinação sexual em aves, PCR, CHD-Z/W. 
VIEIRA, J.N., COELHO, E.G.A. e OLIVEIRA, D.A.A. Determinação sexual em aves via PCR. PUBVET, Londrina, V. 5, N. 3, Ed. 150, Art. 1011, 2011.

\title{
Sex determination in birds by PCR
}

\begin{abstract}
This study evaluated PCR as molecular technique to sex determination in birds using pair of primers allele-specific, $\mathrm{P}_{2} / \mathrm{P}_{8}$, for $\mathrm{CHD}$ gene, located in avian sex chromosomes (Z/W). Electrophoretic result showed two alleles for females $(Z W)$ and one in males (ZZ), being heterogametics and homogametics, respectively. It was observed that there is variation between the sizes of base pairs (bp) between species. These data show that this technique is accurate and secure for sexual determination in birds, therefore demonstrate that gene CHD is conserved in birds.
\end{abstract}

Keywords: sex determination in birds, PCR, CHD-Z/W.

\section{Introdução}

Nos últimos anos, o uso do material genético passou do nível citológico para o molecular (Griffiths, 2000). As tecnologias de análise molecular da variabilidade do DNA permitem determinar pontos de referência nos cromossomos, tecnicamente denominados "marcadores moleculares" (Borba, 2002).

Ensaios de sexagem molecular em aves são geralmente baseados no gene CHD, localizado no cromossomo W, único para fêmeas. Seu homólogo, CHD-Z, é encontrado no cromossomo $Z$ e ocorre em ambos os sexos ( $Z W$ em fêmeas e $Z Z$ em machos). A identificação do gênero baseada na PCR emprega um único set de primers $\mathrm{P}_{2} / \mathrm{P}_{8}$ (CHD-universal) que amplifica fragmentos homólogos de ambos os genes e incorpora introns que geralmente variam de tamanho entre as espécies (Namekawa \& Lee, 2009; Ramos et al., 2009; Vieira et al., 2009; Chang et al., 2008; Anciães \& Nassif Del Lama, 2002; Griffiths, 2000; Fridolfsson \& Ellegren, 2000; Griffiths et al., 1998; 1996). 
VIEIRA, J.N., COELHO, E.G.A. e OLIVEIRA, D.A.A. Determinação sexual em aves via PCR. PUBVET, Londrina, V. 5, N. 3, Ed. 150, Art. 1011, 2011.

Este trabalho teve como objetivo determinar o sexo das aves via PCR, utilizando o par de primers $\mathrm{P}_{2} / \mathrm{P}_{8}$ que é relacionado com os cromossomos sexuais (ZW) das aves.

\section{Material e Métodos}

Para o presente estudo, foram colhidas amostras, de maneira aleatória, de sangue e de penas de criatórios comerciais - Criatório JC e Criatório Lua de Mel, do criatório conservacionista - ZooAmbiental e do CETAS (Centro de Triagem de Animais Silvestres) do IBAMA todos localizados no estado de Minas Gerais, Tabela 01.

\begin{tabular}{ll} 
Tabela 01: Relação entre nomes científico e popular das 15 \\
espécies de aves utilizadas neste estudo, advindos de \\
Criatórios e do CETAS/IBAMA, do Estado de Minas Gerais \\
\hline Espécie & Nome Popular \\
\hline Regulus regulus & Estrelinha \\
Passerina brissonii & Azulão \\
Saltator similis & Trinca-ferro-verdadeiro \\
Sporophila maximiliani & Bicudo \\
Sicalis flaveola & Canário-da-terra \\
Paroaria dominicana & Galo-da-campina \\
Zonotrichia capensis & Tico-tico \\
Sporagra magellanica & Pintassilgo \\
Leninus canaria & Canário-belga \\
Gnorimopsar chopi & Pássaro-preto \\
Sporophila frontalis & Catatau \\
Turdus sp. & Sabiá \\
Ramphastos toco & Tucano \\
Amazona aestiva & Papagaio-verdadeiro \\
Aratinga sp. & Periquito/Maritaca \\
\hline
\end{tabular}

As coletas das amostras de sangue e pena foram realizadas em aves de todas as idades (entre um mês de vida à idade senil), por todo o ano, no período da manhã até, no máximo, às 15 horas. Desta forma não houve mudança nas condições de temperatura do ambiente dos criatórios, não causando agressão ao bem estar dos animais.

As amostras foram obtidas por meio do corte da unha obtendo-se o sangue que foi coletado em papel filtro (Marca Whatman, 55mm), bem como penas que ainda continham ou não sangue no bulbo, novas ou velhas que foram 
VIEIRA, J.N., COELHO, E.G.A. e OLIVEIRA, D.A.A. Determinação sexual em aves via PCR. PUBVET, Londrina, V. 5, N. 3, Ed. 150, Art. 1011, 2011.

armazenadas em envelope. Todas as amostras foram armazenadas individualmente e devidamente identificadas.

Foram feitas extrações de DNA utilizando-se três diferentes técnicas, uma através do sangue pelo método fenol/clorofórmio com digestão pela enzima proteinase K (Sambrook et al., 1989), outra utilizando o bulbo de pena pelo método de extração alcalina simples rápida (Rudbek \& Dissing, 1998) e uma terceira pela tecnologia (modificada) de cartões FTA da Whatman (www.biomerica-inc.com), sendo aqui utilizado papel filtro estéril (Marca Whatman, 55mm).

Cada amostra extraída pelos dois primeiros métodos foi armazenada em microtubo e aliquotada em geladeira, $4{ }^{\circ} \mathrm{C}$, enquanto que pelo terceiro, as amostras foram armazenadas em microtubos em temperatura ambiente.

Foi utilizado um par de primers alelo-específicos, $\mathrm{P}_{2}$ e $\mathrm{P}_{8}$, por amplificarem especificamente os alelos relacionados com os cromossomos sexuais e por serem universais. O primer $\mathrm{P}_{2}$ amplifica o gene $\mathrm{CHD}-\mathrm{W}$ enquanto $\circ \mathrm{P}_{8} \circ \mathrm{CHD}-\mathrm{Z}$ (Griffiths et al., 1998;1996).

O sistema de amplificação da PCR bem como o programa de amplificação foram realizados conforme os protocolos adaptados de Griffiths et al. (1998). Os produtos da PCR sofreram corrida eletroforética, em gel de poliacrilamida $10 \%$, corado com nitrato de prata.

Todos os testes foram realizados no Laboratório de Genética do Departamento de Zootecnia da Escola de Veterinária da UFMG.

\section{Resultados e Discussão}

Diferentemente do concluído por Griffiths et al. (1998), a temperatura de anelamento não variou entre as espécies, pois foi constante, a $49^{\circ} \mathrm{C}$. 
VIEIRA, J.N., COELHO, E.G.A. e OLIVEIRA, D.A.A. Determinação sexual em aves via PCR. PUBVET, Londrina, V. 5, N. 3, Ed. 150, Art. 1011, 2011.

$O$ método de sexagem usando o par de primers $\mathrm{P}_{2} / \mathrm{P}_{8}$ obteve resultado positivo em todas as 15 espécies analisadas. Isto confirma o descrito por Griffiths et al. (1998; 1996) que afirmaram que este par de primers é único, robusto e universal. Sendo, portanto, uma maneira eficaz de distinguir o sexo das aves.

A interpretação das amostras amplificadas foi feita de acordo com o genótipo de fêmeas que são heterogaméticas (ZW), apresentando dois alelos no gel, ou seja, heterozigotas e dos machos que são homogaméticos (ZZ), apresentando apenas um alelo, sendo, portanto, homozigotos (Figura 01). Estes resultados concordam com os obtidos por outros autores, como por Vieira et al. (2009), Anciães \& Nassif Del Lama (2002), Griffiths et al. (1998), Miyaki et al. (1998), dentre outros.

Como é demonstrado tanto na Tabela 02 , como na Figura 01, há diferença no tamanho dos pares de base $(\mathrm{pb})$ entre as espécies, de 246 a 396 para o alelo $Z$ e de 254 a 412 para o W. A Tabela 02 mostra os valores aproximados dos diferentes tamanhos de pb demonstrando a relação espécie-específica dos cromossomos sexuais das aves estudadas.

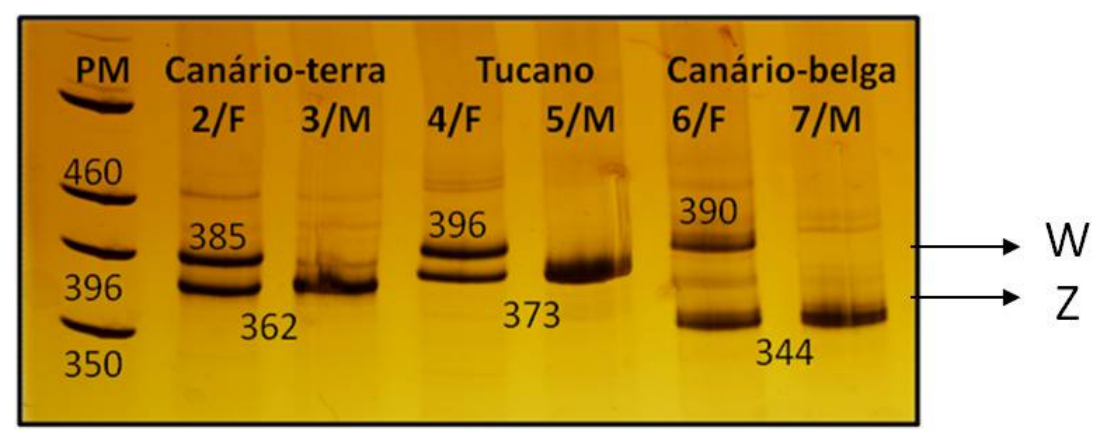

Figura 01: Gel de poliacrilamida $10 \%$, corado com nitrato de prata. PM: padrão de peso molecular pGEM®. Canaletas: 2/F-3/M - Canário-da-terra, 4/F-5/M - Tucano, 6/F-7/M Canário-belga. Os valores dos tamanhos de pares de base são valores aproximados. 
VIEIRA, J.N., COELHO, E.G.A. e OLIVEIRA, D.A.A. Determinação sexual em aves via PCR. PUBVET, Londrina, V. 5, N. 3, Ed. 150, Art. 1011, 2011.

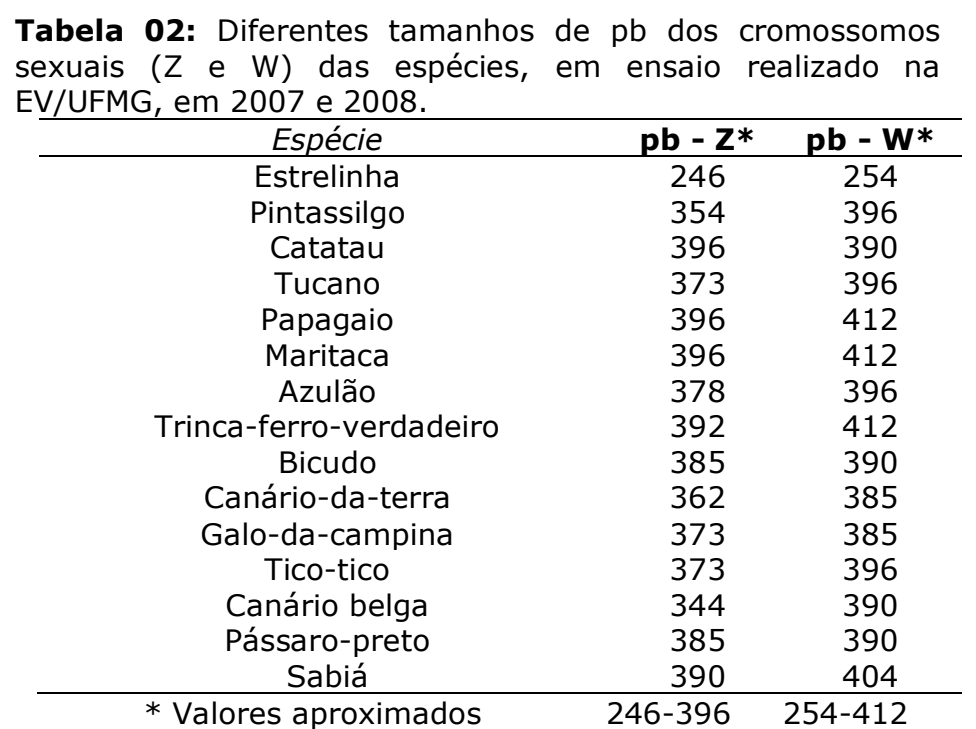

\section{Conclusão}

A determinação do sexo das aves via $P C R$, utilizando o par de primers $P_{2} / P_{8}$, que é relacionado com o gene CHD mostrou-se acurada e segura.

Tanto o sangue como a pena são amostras viáveis para a extração de DNA, podendo a pena ser nova ou velha, com o bulbo vascularizado ou não.

\section{Agradecimentos}

Aos Criatórios e ao IBAMA por possibilitarem a coleta dos materiais das aves. À CAPES pela concessão de bolsa de estudos.

\section{Referências Bibliográficas}

ANCIÃES, M. e DEL LAMA NASSIF, S. Sex identification in pin-tailed manakins (Ilicura militaris: Pipridae) using the polymerase chain reaction and its application to behavioral studies. Ornitolog. Neotrop., 13: 159-165, 2002.

BORBA, V.S. Marcadores moleculares: Classificação e Aplicações, 2002, extraído de http://www.ufv.br/dbg/trab2002/GMOL/GMOL005.htm, em 24/agosto/2006.

CHANG, H.W; CHOU, T. C.; GU, D. L. et al. An improved PCR method for gender identification of eagles Mol. And Cel. Probes., v.22, p.184-188, 2008. 
VIEIRA, J.N., COELHO, E.G.A. e OLIVEIRA, D.A.A. Determinação sexual em aves via PCR. PUBVET, Londrina, V. 5, N. 3, Ed. 150, Art. 1011, 2011.

FRIDOSFSSON, A.K \& ELLEGREN, H. Molecular evolution of the avian $C D H 1$ genes on the $\mathrm{Z}$ and W Sex chromosomes. Genetics 155: 1903-1912, 2000.

GRIFFITHS, R. Sex Identification in Birds. Seminars in Avian and Exotic Pet Medic., vol 9, n०1 (January), pp. 14-26, 2000.

GRIFFITHS, R. et al. A DNA test to sex most birds - Short communication. Blackwell Science Ltd, Molec. Ecol., 7, 1071-1075, 1998.

GRIFFITHS, R.; DAAN, S.; DUKSTRA, C. Sex identification in birds using two genes. Proc. R. Soc. Lond. Ser. B. 263: 1251-1256, 1996.

MIYAKI et al. Sex identification of parrots, toucans, and currassows by PCR: Perspectives for wild and captive population studies. Zoo. Biology, 17:415-423, 1998.

NAMEKAWA, S.H., LEE, J.T. XY and ZW: Is Meiotic Sex Chromosome Inactivation the Rule in Evolution? PLoS Genet. 5(5): e1000493. doi:10.1371/journal.pgen.1000493, 2009.

RAMOS, P. S.; BASTOS, E.; MANNAN, R. W. et al. Polymerase chain reaction-single strand conformation polymorphism applied to sex identification of Accipiter cooperii. Mol. and Cel. Probes., doi:101016/jmcp.2008.12.02; p.1-4., 2009.

RUDBEK, L, DISSING, J. Rapid simple alkaline extraction of human genomic DNA from whole blood, buccal epithelial cells, semen and forensic stains for PCR. Biotechn., 25:588-592, 1998.

SAMBROOK, J.; FRITSCH, E.F.; MANIATIS, T. Molecular cloning: a laboratory manual. New York: CSHL Press, 1989.

SUZUKI, D.T. et al. Introdução à Genética. 7ed., Rio de Janeiro:Guanabara Koogan, 633p., 2002.

VIEIRA, J.N.; COELHO, E.G.A.; OLIVEIRA, D.A.A. Sexagem Molecular em aves silvestres [Molecular sexing in wild birds]. Rev. Bras. Reprod. Anim., Belo Horizonte, v.33, n.2, p.6670, abr./jun. 2009. Disponível em www.cbra.org.br

Site: www.bioamerica-inc.com 